\title{
Technology and the Management of Change from the Perspective of a Culture Context*
}

\author{
DONALD N. MICHAEL
}

\begin{abstract}
The place of technology in the management of change is examined in the light of the cultural environment that mediates that relationship. The utility and limitations of such an examination are emphasized. Some factors that encouraged technological developments in the United States and some behaviors and institutional arrangements that reinforced these developments are specified. The favorable and unfavorable consequences for the management of change today are examined in the context of these persisting culture patterns. Because of the apparant inevitability of social turbulence in the next couple of decades, guiding social change to a different and appropriate valuing of technology, with corresponding changes in behavior and institutions, will require the development of social theory and technologies far beyond those presently available. The chances of succeeding seem slim.
\end{abstract}

If one defines a crucial characteristic of modernization as being an activity that extends into the future, then modernization necessarily becomes a problem in the management of change. But the meaning of management, of change itself, and the context for engineering particular changes either by political means or by those of organizational or individual development, all will depend on the culture characteristics of the society. Of the many culture characteristics that must be attended to in such change management approaches, I will focus here on the relation of technological change to social change as mediated by the culture context. I will emphasize technology because, in the United States, the creation and availability of increasingly complex and powerful technologies have, to the extent we understand social process, contributed enormously to and, until recently, have been reinforced by the particular culture characteristics of that society. Technology is not the only factor that needs be attended to in order to appreciate the nature of the task of managing social change. But, to the extent that modernization is dependent on the availability of technological resources and technological prowess, the ways technology is valued and used may tell us important things about the culture prerequisites for managing social change.

There is in the anthropological literature a continuing debate on the nature of culture

DONald N. MiChaEl is Professor of Planning and Public Policy; Professor of Psychology; and a Program Director, Center for Research on the Utilization of Scientific Knowledge, at the University of Michigan.

* Invited address to the Second International Conference on Problems of Modernization in Asia and the Pacific sponsored by the Center for Cultural and Technical Interchange between East and West, August 13, 1970, Honolulu, Hawaii. The Proceedings of that conference will be published by the Center late in 1973. I am indebted to it for permission to publish my paper here. The preparation of this paper was facilitated by, and derives from, research conducted under Special Research Grant MH 14629 of the Center for Studies of Metropolitan Problems, National Institute of Mental Health. 
and the objective evidence for this abstract concept. Of the definitions and theories that have been argued among anthropologists, certainly those of Clyde Kluckhohn rank among the most influential. Partly because he was my mentor and partly because his definitions are particularly useful for our purposes, I will apply the concept of culture in keeping with his ideas as set out in his chapter, "The Concept of Culture," published, appropriately enough, in The Science of Man in the World Crisis[1] . I quote:

\begin{abstract}
A culture is a historically derived system of explicit and implicit designs for living, which tends to be shared by all or specially designated members of a group. (p. 98.) A culture is not only a reticulum of patterned means for satisfying needs but equally a network of stylized goals for individual and group achievement. (p. 104.) Almost no human situations are viewed in ways which are altogether a consequence of the individual's experience. Culture is-among other things-a set of ready-made definitions of the situation which each participant only slightly retailors in his own idiomatic way. (p. 91.) Cultures create needs as well as provide a means of fulfilling them. (p. 81.) Cultures create problems as well as solving them. (p. 81.) Most specific needs can be satisfied in a wide variety of ways but "the culture selects" only one or a very few of the organically and physically possible modes. "The culture selects" is, to be sure, a metaphorical way of speaking. The original choice was necessarily made by an individual and then followed by other individuals (or it wouldn't have become culture). But from the angle of those individuals who later learn this bit of culture the existence of this element in a design for living has the effect of a selection which was not made by these human beings as a reaction to their own particular situation but was rather a choice made by individuals long gone but which still tends to bind our contemporary actors (p. 95.)
\end{abstract}

In other words, we are attending to the patterned set of values and behaviors that people hold about what is right and worthy and wrong and undesirable, and it is that set of values toward technology and its utility and the expected behaviors expressing those values that we will examine [2].

Some preliminary comments are in order, however, about the limits of approaching the management of change through the concept of the cultural environment. In the first place, the concept of culture is an abstraction as is the concept of society. These concepts are not precise and their imprecision is made greater by the pervasive lack of useful data about how men actually behave in their social and institutional settings. Such data would permit us to refine these concepts and to judge better their applicability to on-going circumstances. Presently, we simply do not have enough data: we literally do not know what we are talking about much of the time when we claim to be describing and analyzing the behavior of men and institutions either as it has occurred in history or at the present time-to say nothing of the future. In the United States, a growing awareness of the need for social indicator data is evidence of an appreciation developing at the political as well as academic level that, in fact, we do not know what is happening well enough to check which of various theories are appropriate for explaining and predicting what is happening. Not only do we lack data about what is happening now, but we lack data about how the present came to be. That is, we lack longitudinal data that records over time how men effect and are affected by their social and technological environment.

All of these comments hold with particular emphasis when we are trying to understand the role of technology with regard to social changes. Data-based knowledge is prerequisite to the development of appropriate schemes for the management of change particularly in the light of the potentialities and the problems inherent in new technologies. Hence, what I have to say, indeed whatever anyone says, about the relationship of technology to social change is necessarily speculative.

There are many studies which attempt with considerable useful insight to relate one or 
another set of factors which seem to be of particular pertinence, but I must emphasize that we presently lack the methods and the data for generalizing these interpretations and for projecting them into the future. To be sure, within groups of observers there can be found concensus about what is happening to society. But this is more an indication of how people protect, maintain, and elaborate the vested interests of their subcultures through what they pay attention to than it is evidence of the validity of viewpoints held. And, of course, what is attended to is, to a large degree, culturally determined through the definitions of what particular groups ought to pay attention to. Indeed, it is only with the growth of concerns such as those which are focused on in this conference that time, effort, and approval will be applied in sufficient degree to begin to provide us with a firm foundation for analyzing and forecasting the relationship of technological change to social change in a given cultural context.

Cultural and social change is also a function of the cultural styles available for dealing with changing expectations and values of both the active and passive members of society. It is not only the values held and behavior expressed, but it is the culturally-guided dialectic occurring among changes in values and behavior as they are occurring that influences change in social process and, thereby, complicates the task of managing change. To the extent that technology facilitates or inhibits changes in values and behavior, it affects the patterns of values and behavior and, hence, the cultural setting for further change.

Social change, and the technological change intertwined with it, is also very much a consequence of the idiosyncracies of individuals and of history. The societal traumas or successes that individuals or events confer on society leave their traces in the patterns of expectations and the procedures for justifying and carrying them out: they modify, even as they are modified by, the culture patterns up to that time. These sudden and unexpected concatenations of men and events will become all the more likely and all the more significant in an increasingly dense, interactive, and technologically interdependent setting. Hence, I would argue that the effects of idiosyncratic circumstances will increase as the degree of modernization increases.

What we are increasingly confronted with is a turbulent social environment. Those acting through institutions or through technology cannot know with certainty beforehand what will be the most likely or significant consequences of their acts because the social environment itself produces large effects independent of or unanticipatible from the deliberate acts of man and technology that are aimed at managing that environment. Thus, the task of cultural analysis and the application of that analysis to the management of change become extremely complicated as the secondary and tertiary consequences of the interaction of behaviors and technologies become at least as important as the initial consequences of the impact of a new technology. Managing the primary effects is, in a sense, the least of the problems involved in managing social change.

We shall examine more specifically such secondary and tertiary consequences later when we shall see that the cultural circumstances that have facilitated the development of high technology, and hence modernization, in the West now appear to be the very ones that may very well undermine most, if not all, of the social edifice as it is now constructed. As we explore the culture context for technological development and social change in the United States, it is necessary to keep in mind that the present situation is in profound flux. Essentially, all the cultural "givens" that we shall examine are now being challenged as to their moral rightness, their utility, or their priority. This questioning of the legitimacy of institutions and the beliefs used to justify their actions is profound and 
itself appears to be a consequence of the development of a highly technologized society.

Thus, it should be understood that in the first part of what follows, I will describe some cultural circumstances that gave underlying support to the development of the United States along lines that produced and responded to the impact and impress of technology. Later, we will examine some of the changes in culture that seem to be occurring and those that can be anticipated in the future during the period when the modernization we are concerned with here will be unfolding.

In summary, what I have to say is inevitably conjectural in three senses. In the first place, my comments are culture-bound and, hence, of unknown generalizability especially to Asian and Pacific cultures about which, most regretably, I am profoundly ignorant. In the second place, even within a culture perspective, the interpretations of what is happening are of unknown validity. In the third place, one can say very little about the future in view of the almost certain pervasive effects of unanticipatible events. In the interests of style, I will not precede each statement with "I think" or "it seems to me and other observers," or "it appears that." But these qualifications are always there.

With these caviats in mind, let me describe the structure of this paper. First I will discuss some culture characteristics that have encouraged technological developments in the United States. Second, with these characteristics in mind, I will look at some kinds of behaviors and institutional arrangements that support, and thereby reinforce, these culture characteristics. Third, we will consider some of the consequences today for the management of change in terms of the negative and positive consequences of the persisting culture patterns. And fourth, we will focus on the consequences anticipated for tomorrow: the inevitability of social turbulence as a source of change leading to new culture forms with a different valuing of technology, and the different behaviors and institutions for facilitating these values which will result from this process.

Let us turn to beliefs and expectations regarding the directions of technology and the nature of those who direct it. Certainly, the most pervasive assumption held about the relation of technology to the rest of society was that progress, which was believed to be the desirable and attainable direction of society, is the inevitable consequence of the use of new technologies. While lip service was given to other means for advancing the society and distressed questions were raised by some, the most popular ideology and the general expectations were that progress would come through technology and that progress is desirable; hence, technology is desirable. Typically, "technology" referred to material technology first and biological technology more recently. Traditionally, social technology-social engineering-has not been included in this category.

Intimately related to equating progress and the common good with technological development was a basic optimism about the future [3]. This optimism developed from religiously-related beliefs that we were ideologically blessed and from a belief that our increasingly powerful technologies would give us the capabilities for manipulating the environment, both man and material, to the ends we choose. This optimism about the future pervaded not only our sense of what we could become domestically, but also what we could accomplish internationally. Internationally, our future was believed secured (1) through military supcriority achievable via technological superiority, and (2) through our productivity and the marketability of our products also achieved through our superior technology.

A further piece of the interlocking set of supporting beliefs and expectations about technology was that there were no limits on the degree to which men and resources could be harnessed to, and rewarded by, the expansion of technology. Natural resources were 
thought to be infinitely replaceable or substitutable through new technologies, and human wants were believed infinitely expandable. Hence, the capacities of humans to consume the products of new technology were unlimited. Related to this state of mind was a firm belief that the only healthy economy, hence healthy society, was one that showed continual growth in the Gross National Product. Since progress equals expanding technology which results in expanding productivity, then the GNP must expand too.

This capability of technology to expand to meet old needs and to develop new ones depended in part on the belief that men could and should be organized to achieve anything via technology that seemed important to achieve. The expectation was that by rationalizing activities through efficient management, accounting, and work techniques and, more recently, through operations research, systems analysis, computers, and the like, men could be organized to carry out enormously complex activities that would result in the development and application of new technologies. The invention of arranging men into inventing organizations was, for the most part, a World War II development, and belief in the prowess of this organizational technology to develop other technologies has grown rapidly since then and will continue to grow in most corporate and government quarters. The most recent expression of this expectation is the often-repeated assertion that putting a man on the moon demonstrates that we really can accomplish what we want, if we only have the will to do so. This view, which makes social reality just another version of technological reality, is so obviously distorted that its appeal can only be explained as the consequence of the kind of selective filters culture puts between men and their environment.

Since most technological development was done, or was believed to be done, through private corporations, this arrangement supported the traditional belief that a pragmatic, entrepreneurial, free-enterprise approach was a more reliable and rewarding path to progress than was government planning. The evidence was ample that men and machines could be organized opportunistically to produce other machines to deal with new problems and opportunities. Since American success with the development and use of technology had been experienced chiefly through the entrepreneurial, pragmatic set of beliefs and behaviors about how to do things, there was little incentive for, and deep cultural resistances against, shifting to a government planning approach for choosing among technologies to be exploited in the public interest. The way to progress was through the ad hoc interaction of private interests, each exploiting technological possibilities as the opportunities appeared attractive to them.

Now let us look at some behaviors in their individual and institutionalized forms which expressed and supported these patterned expectations and values regarding technology and which made them into self-fulfilling prophecies. Characteristic of the arrangements defining a culture, these discouraged examination and implementation of alternative societal arrangements.

Perhaps the most crucial factor was the institutionalization of the Protestant ethic, which, according to at least one influential and seminal interpretation of the history of the West, encouraged compulsive attention to entrepreneurial activities, since the evidence of eventual access to a heavenly after-life was demonstrated through success in this world [4] . Entrepreneurial motivations and opportunities were furthered by the expanding variety of possibilities for success that technology made possible. In a nontechnological society, the means for demonstrating accomplishment were prescribed and limited. In a society exploiting technology, the opportunities were unlimitedly great for developing new markets and discovering new uses for the capabilities of the technologies, and they 
were so used. In this way, the exploitation of technology required the development of complementary new life styles, roles, and statuses.

Facilitating this was the high value placed by the culture on achieving status rather than being legitimized by an ascribed status[5]. Evidences that people were valued for their personal achievements, rather than for their family or clan affiliations, contributed to the belief, at least among white people, that one could achieve success and to fulfillment of that belief. Since there were comparatively few barriers of tradition and privilege which obstructed the achievement of success through one's abilities to manipulate the natural and social environment, and since many ways of manipulating the environment were new, made possible by the technology, more opportunities for achievement were always arising. These new ways would have been inhibited if tradition, convention, and status by ascription had dominated the value system.

Mass public education was a third institutional form for producing behavior that furthered the beliefs and expectations about the utility and consequences of using technology. Mass education ingrained expectations and behavior for roles as producers and as consumers. Thereby, many people learned skills that could be applied to production, to the management of production via new technoiogies, and to the creation of new technologies. Equally important, they learned a set of values that stressed the desirability of consuming the products of the technologies, and the capabilities of technology to provide the basis for an ever-increasing standard of living, national prowess, and Gross National Product. Fundamentally, American mass education was designed to incorporate immigrants into the dominant culture style and, thereby, to produce people in resonance with the technological and managerial requirements of the times.

In recent years, the invention of management technologies designated to forward technological development more efficiently has reinforced the beliefs about technology, national growth, and its management. Management-facilitating systems are developed and disseminated by business schools, organizations providing current information about new management techniques, private organizations that train executives in specific management techniques, and many periodicals. More recently, the management field has included techniques such as program budgeting and planning, operations research, and systems analysis. Some of these techniques first demonstrated their utility during World War II and subsequently in the U.S. Department of Defense. Again, the high status accorded to technology applied to national security has served to give initial legitimacy to these techniques, i.e., if they are good for defense technology they must also be good for other parts of society.

Related to this set of managerial behavior technologies is the style of behavior deemed appropriate for members of task-oriented groups or corporate entities. Largely culturally determined, this style puts heavy emphasis on rational behavior and the repression of the emotions. This emphasis on the rational with its concomitant repudiation of feelings in interpersonal relations has been demonstrated to be very costly to effective management [6]. Nevertheless, so strong has been the cultural cannon against showing feelings in task-oriented, interpersonal behavior that only recently have some organizations begun to experiment with more creative forms of management. There is a small but growing application of knowledge about group process and interpersonal behavior to the technology of managing technology, and, there are many experiments under way with new management forms and new ways of operating task groups at all levels of organization.

While these techniques appear to have demonstrated considerable ability to increase organizational efficiency and flexibility, they carry with them two important conse- 
quences. On the one hand, there is the tendency for these techniques to be used to manipulate people into more efficient "cogs" in the organization; that is, organizationdevelopment technology is used with the intent of altering people in the same spirit as technology is used to alter inanimate forms of matter. Necessarily, this corrodes those values in the American culture that emphasize the integrity and autonomy of the individual. On the other hand, since these techniques also tend to facilitate more widespread participation in decision-making they tend to lead to revisions in the definitions of power and status and the arrangements that support and enforce them. It is not mere coincidence that efforts at participant management, sensitivity training, T-group training, and so on shade-off into encounter groups and a variety of experimental activities that attract people seeking new ways of life that often reject the technological and the bureaucratic.

An important consequence of the circumstances we have been discussing has been that most people in the United States have experienced the consequences of technological development chiefly through personal purchases of items that enhance their sense of well-being. Since technology enhances their sense of well-being, they tend to project their personal experiences onto the whole socicty. That is, they feel a rewarding relationship with technology since they are able to select from an increasing number of rewarding options as a result of a higher standard of living in large part created by greater productivity resulting from better technologies. Thus, individuals who can afford the personal benefits of technology have been drawn away, so to speak, from attending to the appalling consequences the accumulation of affluent, individual choices have had on the natural and human environment as a whole. This selective perception contributes to the lack of institutional arrangements for the support of technologies for the public welfare which cannot depend for direct support on the existence of a market clientele. This is most evident in the areas of pollution control and environmental quality in general as well as in areas such as mass transport, low-cost housing, and truly good education. There are, of course, other obstructions to the development of public welfare technologies. Some arise from corporate preoccupation with products that involve minimum risk and reorganization; in government agencies they amount to analogous preoccupations with bureaucratic protection of their special constituencies. But, overall, the emphasis on private consumption and the rewards of private consumption, which encourage that emphasis, have discouraged attention to investment in social welfare technology.

These expectancies and values about technology, interacting with technological developments and other processes in the society, cvolved into the form we recognize today of a highly developed technological society with enormous, indeed, outrageous disparities between its greatest and its least accomplishments. These disparities offer increasing evidence of the inadequacy of just these life styles we have reviewed for trying to manage social change partially through the use of technology. What is becoming clear to observers, including some in government and industry, is the absolute need for some sort of planned social change, for long-range planning that extends over a decade or more. But this need implies an equally pressing need for basic changes in the values and expectations held and behaviors practiced--the culture pattern-so that social change management philosophies and activities can be implemented in a very short time. The short time requirement seems crucial: as I shall argue subsequently, it appears that, in the United States, survival of a social system based on our conventional interpretation of a democratic philosophy is highly problematic, and the risks to its survival are becoming greater the longer it takes to get major changes implemented in the management of that society. 
Note that I am not saying that the technology for social, long-range planning presently exists. Rather, I am saying that the beginnings of such a technology do exist and the necessary circumstances for its further development depend on deliberate efforts to utilize and refine it. To date, these efforts have been lacking for the most part.

The development of the United States under a culture pattern that encouraged an essentially ad hoc, laissez-faire approach to technological elaboration, appears to have produced a state of affairs of such complexity and difficulty that it is really impossible to see how to get from the present into a desirable future in a coherent, deliberate, and politically democratic manner. In effect, the United States faces enormous problems pertinent to the management of change, problems of modernization or, better, postmodernization, that are analogous to those in Asia and the Pacific. It is increasingly evident that, just as many culture values in other parts of the world are contradictory to the conditions needed for modernization, so too the traditional culture pattern in the United States is contradictory to the conditions necessary for postmodernization. Our crises in governance, in the management of control and freedom, are similar to those in other parts of the world that are far less dependent on high technology.

Let us, therefore, now attend to those residual traditional values and styles which seem contradictory to the needs of today, to the needs of a society in important part created out of the interactions of those traditional values and styles.

First, there is widespread resistance to long-range planning by government. Planning as perceived within the traditional set of behaviors and values implies control, loss of autonomy, and loss of those entrepreneurial conditions which have allowed so many people to become so successful, often at the expense of so many others, and to jeopardize the natural environment to which man's survival is ultimately linked. The resistance to planning grows out of the state of mind associated with the learned success of nonplanned approaches to societal development, and out of an apprehensiveness toward risking restrictions on "doing one's own thing," to use the contemporary phrase. The resistance to planning also derives from the positive value put on one meaning of pragmatism. For Americans, pragmatism is often perceived as the equivalent of expedient activity sufficient to the moment at hand. It is much less often perceived as the proper philosophy for evaluating in a longer time context the appropriateness of the means used. Many people raised and rewarded by the traditional culture view their world as one that is still relatively segregated and relatively noninterdependent; they expect that there always will be room for expansion (the frontier philosophy), that social interdependence is low, that what there is is encompassible (the small town, low population, and low eventdensity philosophy), and that whatever goes wrong can be rectified by further deliberate actions (the optimistic, "technological-fix" philosophy). All of these expectations and reinforcing behaviors sustain a lack of appreciation for the need for interactive, interdependent behavior, and hence for planned behavior. Planned behavior is needed to compensate for the absence of culturally defined behavior and values that, of themselves, would constrain behavior to that which is compatible with high levels of interdependence and interaction. Such a culture pattern does not exist for most of the population.

In the light of what we know about how attitudes and beliefs are reinforced, such values will follow after experiences which make one kind of living rewarding and another punishing. Probably, we shall have to plan first and then, out of the consequent experiences in living with these plans, may grow the values that can replace part of the planning behavior itself. If people learn to live in ways that assume intense inter- 
dependency, then behaviors that are expected and valued will of themselves serve some of the directing purposes that planning now would substitute for.

Another increasingly inappropriate culture style still offers substantial rewards for most of those who have grown up within it: this is the hierarchical structure which characterizes interpersonal and intraorganizational relationships in most organizations, in particular in corporations and government. The essentially pyramidal organizational arrangement grew out of more primitive culture patterns of family structure and predatory and defense tactics. It was reasonably applicable to comparatively simple organizations with stable task allocations and simple response patterns, a situation that also characterized the earlier years of technology utilization. Furthermore, the bureaucratic structures associated with organizational pyramids did have the virtue of rationalizing the services the organization provided by insulating the organization from the environment. It insulated the organization, in part, in order to limit the amount of disruptive information coming into the organization so that there would be sufficient organizational stability to respond to stable environmental demands. This, thereby, made services, particularly those provided by governments, less subject to corruption and caprice, and more reliable. However, as a result of the development of an increasingly differentiated environment that made an increasing variety of demands on the institutions serving it, and as a result of the increasing number of consequences produced when these institutions insert new technologies into the society without sufficient preplanning and control, the bureaucratic structure has become, by its very nature, comparatively rigid and unresponsive.

What are now needed are "disruptable" organizations, so to speak, which are better able to respond to a variety of rapidly changing demands from the environment by being better able to make transformations within the organization. The pyramidal structure, the bureaucratic structure, cannot accomplish this. But, it is particularly difficult to shift structures when organizations feel themselves challenged, besieged, under stress-the conditions of today. When confronted with such challenges, those who have succeeded by leading organizations to their present condition usually try to retreat, in a typical human manner, to patterns of behavior which worked in the past. For that very reason, they are unlikely to work in the present. But short of catastrophe and deep crises, when organizations seem most open to change, the tendency is to cling to rigid, unresponding structures.

Closely related to the conditions just described is the set of values and expectancies in the culture that traditionally has made it difficult, if not impossible, for public and political figures to acknowledge, to embrace, error in public. That is, United States tradition sets a high value on not being wrong and, indeed, partly defines its leaders as those who have the ability to be right. Error has an aura of sinfullness about it or, at least, of reprehensible inadequacy. Hence, public figures pretend error didn't happen or, if it did, it was someone else's fault. Error is punished; success is rewarded. The belief that one ought to be able to succeed is especially reinforced by expectations about our ability to control our actions, expectations applied to the human realm that derive from successes we have come to expect in the technological realm. Many counterproductive consequences thereby arise. In particular, there is great reluctance throughout government and corporations to be truly innovative because the uncertainty in the situation is so high that the chance of error is also high. Thus, it is seldom worth the personal or economic risk for successful members of organizations to champion innovation when circumstances are sufficiently rewarding without doing so. 
Embracing error as a positive virtue is a requirement for effective long-range social planning because all such planning, if it is to be humane and responsive to reality, must be flexible with regard to reevaluation of goals and priorities and the means for realizing them. Planning must include an explicit moral obligation to learn from what goes wrong. Such an approach, which assumes that the future is highly uncertain, runs contrary to the deep-lying optimism referred to earlier. It also runs contrary to the pragmatic definition that one can always rectify a situation and that "too little and too late" is not really a plausible outcome.

One basic cultural shift required to make error-embracing feasible would place social experiment and social development ahead of reelection. Politicians at all levels in the United States set-and traditionally are expected to set-reelection as their prime obligation and have seldom been known to jeopardize reelection in the interest of more tenuous, long-range aims for this society. Clearly, such a shift in political values and styles would necessitate profound changes in the American social system. Among other things, it would carry with it the need for long-range political stability in order to cope with short-range, as well as long-range, social turbulence. How these needs might be reconciled is completely unknown at this time.

In addition to the counterproductive residual cultural characteristics, there are residual cultural characteristics which are especially compatible with the requirements for the management of social change in a postmodernized society. In the first place, traditional modes of optimism and pragmatism can operate as culture characteristics that encourage shifts in values towards planning and the gathering of social information as a basis for taking action. That is, some spokesmen take the position that there are great things that we should and can do and that these will take longer to do and are more important to do than other things we have done. They feel that we have to get organized to do them; that we must plan so we can do them. So far, this mood is chiefly rhetoric and it remains to be seen whether those espousing this value position will be able to recruit and develop the behavior needed in others or, indeed, if they themselves understand the implications of their position. However, one indication that this movement may gain strength is the increasing altention being given to the need to collect social indicator data as a basis for knowing what is happening and for doing something about it. Since such data reflect both the moment and change over time, they are necessary (but not sufficient) for planning. Also encouraging are expressions in Congress and professional organizations of the need for, and interest in, doing longer-range technological assessments as a basis for deciding whether or not it is in the societal interest to produce particular technologies and how to apply them. This, too, is still at the rhetorical or at the introductory legislative stage and it remains to be seen how seriously these new value priorities will be taken when the changes in behavior needed to fulfill them become explicit.

The value placed on achieved status over ascribed status can be seen as carrying with it an inherent questioning of legitimacy whenever any of those who have achieved status are encouraged to retain it so long and so unquestioningly that it becomes, in effect, ascribed at least to the extent that the behaviors and values associated with it are treated as if they were self-evident and unquestionable. Hence, the questioning of legitimacy which is presently disrupting the United States also carries with it the potential for reallocation of status and power and the values that underly these, and, thereby, the potential for organizational invention and innovation. The potential for social experimentation is great within this mood of questioning legitimacy. But so too is the potential for social disaster through the disolution of cxisting shared patterns of expected behavior. Without such 
shared patterns men are unable to assign priorities and allocate resources over long enough time periods and on a large enough scale to meet social needs even poorly.

As suggested earlier, the development of a management technology bodes both well and ill. It is worth discussing again in this context as an example of a favorable expression of a residual traditional culture pattern when related to the pragmatic approach and to the belief in the virtues of technology. In the management technology field there are a number of humanitarian psychologists and executives eager to enhance the opportunities in job settings for creativeness and fulfilling work. As a result, a number of experiments are under way which attempt to redefine conventional organizational power to allow participants the scope to be more productive and creative. These experiments depend on the deliberate, self-conscious examination of self working with others, task-group processes, and shared goal-setting responsibilities. As such, these efforts are in the rational tradition of the West, in the technological, optimistic tradition which treats self as something capable of deliberate change and growth. This need not necessarily demean the sense of individuality. Indeed, it is an opportunity to enhance sense of self and of others since an atmosphere of trust is produced and, with it, greater incentives to risk uncertainty and innovation. These experiments in both voluntaristic and corporate settings appear to be rewarding in terms of personal satisfactions and organizational effectiveness.

I will turn now to anticipating some consequences of the interplay between the positive and negative aspects of these residual culture values as they may affect the place of technology and the management of social change. In this way, we will see additional challenges that a postmodernized society faces in dealing with the culture premises which have made it a highly technologized society. And, since one way or another the modernizing nations will have to deal with whatever conditions exist in the postmodernized societies, we will better appreciate also the additional challenges for those nations seeking to modernize themselves. It is in this way that futurist conjectures become essentially pertinent for modernizing efforts. For, while it can be argued that the most pressing problems of these nations are those that exist right now, these problems, by their very nature, will only be solved in the future-five, ten, twenty years from now. They exist now, but they cannot be solved now. Hence, plausible future circumstances become crucial for planning now how to resolve these problems over future years. Plausible future circumstances become the context for choosing among alternative procedures for planning solutions to present problems. Thus, the future is the present for modernizers. It can only be ignored if the future is assumed to be the same as the present. And, as we shall see, the future of the postmodernized societies is certain to be much different from the present and past situation. Thereby, the situation will also be different for modernizing societies to the extent they will be interdependent with the postmodernized societies.

All evidence suggests that, at least for the next couple of decades, the United States will be a highly turbulent society more likely than not, demoralizing itself into a splintered, culturally amorphous state of chronic social crises and catastrophe. The turmoil arises from an increasing questioning of the premises underlying the society and from the divergent and various behaviors associated with that questioning. Al the same time, there is a growing lack of adequate forms of governance, negotiation, mediation, and constructive control. This lack can be ascribed to three general conditions.

First, the very challenging of the premises of the culture from so many and from such widely diverse sources as young versus old, black versus white, rich versus poor, and white collar versus blue collar, presents the society with a situation that a viable culture 
patterning does not face, by and large-namely, its own undermining. Hence, there are no institutions that are really effective for dealing with this state of affairs. Dissent has always been constrained to expression and action within the rules of the game. Now dissent includes rejection of the rules. The culture has no means for coping adequately with its own rejection, so to speak.

Second, we are subject to a new property in this type of social system: because of large population size and the high frequency of repetitive events, very small percents of people or events now become socially perturbing. This is so whether it be an unlikely but now frequent tanker break-up or ghetto riots or protests by a small percent of housewives, hard hats, or hippies.

Third, there is the very complexity and interdependence, the fragility of the society, with its vulnerability to the unanticipated adverse consequences of technologies whether it be oil leaks, inversion layers, nuclear explosions, or the high-speed exchange of emotions, made possible by TV. There are no adequate forms of governance for comprehending, anticipating, and dealing with the scale, variety, and speed of interactiveness of the men and events in the society. Hence, all traditional approaches are likely to be relatively inadequate, and all new approaches are likely to have a high rate of failures as would any experiments performed under such relatively blind and complicated conditions. Thus, United States society is bound to be in a state of continual high turmoil.

Add to this the longer-range unanticipated ecological burdens imposed on the environment and the men in it by the sheer numbers of people using, wasting, and polluting their environment. Add further the more obvious consequences of thermal pollution from nuclear reactors and other forms of environmental distortion from chemical pollutants. Necessarily, either the environment will steadily deteriorate, thereby multiplying the turbulence of the social situation, or a major reallocation of resources will have to be put into preserving the environment. Such a reallocation will impose novel behavioral constraints on large numbers of organizations, people, and styles of life. This will further increase turbulences.

In such a societal and environmental situation we can expect alternative and simultaneous periods of repression and licensc as the society, through formal and informal modes of governance, tries to cope with turbulence either by repressing it or allowing freer reign. The former approach cannot solve the problem of turbulence: repression will generate reactive turbulence since the society is too big and too heterogeneous to repress totally. License generates social frictions, unpredictability, and, thereby, more turbulence. But it also provides opportunities for discovering and synthesizing new styles of conduct. There is, to my mind, a slight hope-but only a slight hope-that from these, with luck and wisdom and deliberate research, we will learn enough about the appropriate culture base for such a society to be able to establish the conditions for managing a society of this complexity. What that set of values and expectancies might be is not presently evident. There may be glimmers of its characteristics in the behavior of some of the groups of young people with their experiments in sharing and commune life. However, these expressions seem to be more residues of past utopian ideals, derived from a simpler day when the facts of technology and social complexity did not exist.

If a stable culture pattern is developed, it is entirely reasonable to expect that technology will no longer be seen as an inherently positive expression of man which should be left to its own efflorescence and proliferation. Rather, technology and its development and utilization will be increasingly a matter subject to careful evaluation in a setting of human need values that are more primary and determining. To ask what these 
values and procedures would be and when they will be in operation would be much like asking members of feudal culture to characterize the yet-to-be-evolved culture based on a money and market economy. They simply couldn't do so: the experiences upon which to base the concepts didn't exist.

As the United States and, quite possibly, Europe and other highly industrialized areas go through the anguish and crises of discovering that their culture bases are inadequate for providing the rewards, goals, and governance needed in a highly technologized society, these traditional Western culture models will become increasingly less attractive to those areas of Asia and the Pacific seeking to modernize themselves. The cost of technological modernization, United States style, will become more evident to them as time goes on. But, the costs of not modernizing are already evident. Confronted with this dilemma, we can expect that all areas of the world will have to struggle with the terrible and exciting challenge of trying to discover forms of life and the values underlying them that one can reasonably hope will provide the rewards of technologically based society without the outrageous costs which are becoming more and more evident. The outcome of that struggle is, to my mind, unpredictable. If it is successful, the culture forms will very likely be quite different from what we might imagine them to be.

The task will be extraordinarily difficult-if it can be done deliberately at all. Whatever else it requires, it is necessary that men in power come to use knowledge about society's workings, about future possibilities, about themselves, far more broadly and easily than now is the case [7]. Contrary to the myth in the West that "if you build a better mouse trap, the world will beat a path to your door," the clear facts are that the inventor usually has to drag the world kicking and screaming to even look at his trap. This is especially true when we are talking about getting knowledge used that is innovative with regard to man and society: cultures are designed to screen out all but certain innovations, as the earlier quotations from Kluckhohn emphasize. So far, it looks like both Eastern and Western cultures are designed to screen out innovations of the sort that would be needed to manage humanely a huge world of men and machines, but of limited resources.

If we are to find a way out, it will require that we come to value highly the application of new knowledge about men and institutions. We are developing some technology that facilitates knowledge utilization but for the most part we simply know better than we did how little we know about such a technology. This technology needs to be applied to changing institutions and organizations so that they can effectively meet the changed conditions that render them inadequate, so that they can do long-range planning, and so that they-the men in them-can easily embrace error and quickly learn therefrom. We now have the beginnings of a technology for changing organizations-but only a beginning. And we need to develop a technology for designing institutions and organizations that can respond effectively and humanely to the turbulent environment I described earlier. With regard to this requirement, we do not have even the beginnings of such a technology: We are only beginning to develop the theory [8].

I can only conclude that, given our problems in the East and West, and given our primitive social technologies for dealing with them, we are bound to experience more social turbulence and many social calamities. This social context means that it will be harder to do the research and development needed to improve the social technologies described above. However, disasters and crises provide the easiest occasion to initiate organizational innovations and value changes. The problem is to be ready beforehand with the means for increasing the likelihood of establishing the desired change when the disaster provides the opportunity. But this means putting a major effort into crises and 
postdisaster planning. And this requires acknowledging that the chances are poor of averting crises and disaster, and that we must prepare for the worst. Men in positions of leadership and power have an almost impossible time doing this. In terms of the culture values East and West, such acknowledgment is politically suicidal. At a deeper level, such acknowledgment means that successful men-including you and me-must accept that their very image of themselves as successful is now and henceforth wrong. We must acknowledge that we really know very little about how to deal creatively with tomorrow. We need to acknowledge that, somehow, we have discovered and are ensnared in a new wilderness, a new jungle, and that the skills that got us here are inadequate to get us out. Looking around us, we must acknowledge that we really are lost.

Will we find our way out? That depends at least on recognizing that we do not know where we are, and on drastically reordering our beliefs and behaviors so that we can begin to try to find out. This reorganization itself may not be enough; it may not come in time. But it is the least we can do and the first thing we must do. Can we do it? I doubt it, but none of us understands the dynamics of societies well enough to be sure. So I shall continue to try.

\section{Notes and References}

1. Clyde Kluckhohn and William H. Kelly, The concept of culture, in The Science of Man in the World Crisis, Columbia Univ. Press, New York (1945), pp. 78-106.

2. It should be kept in mind that in all but the simplest cultures there are subcultures. These share the major patterns of the culture they are part of, but they also possess different characteristics than do other subcultures within the culture. The relationships among the subcultures are patterned and the distinctive characteristics of the subcultures serve specific functions within the overall culture pattern. For example, in complex societies the culture characteristics of the intellectuals differ from, say, those of rural people, but, within a society, they share certain beliefs and behaviors and their interrelationships are patterned.

3. Robert L. Heilbroner, Optimism and the idea of the future, in The Future as History, Grove Press, New York (1961), pp. 16-18.

4. R. H. Tawney, Religion and the Rise of Capitalism, Harcourt Brace, New York (1926); since reprinted in several paperback editions.

5. Talcott Parsons, An analytical approach to the theory of social stratification, in Essays in Sociological Theory Pure and Applied, Free Press, Glencoe, Ill. (1949), pp. 166-184.

6. Chris Argyris, Organization and Innovation, Dorsey Press, Homewood, Ill. (1965).

7. I am referring specifically to scientific knowledge. But I am also including that knowledge that has to do with values and, thereby, with alternative definitions of the nature of man and the worthy life.

8. The general problem of redesigning organizations so that they can learn to do long-range social planning is examined in detail in D. Michael, On Learning to Plan-and Planning to Learn: The Social Psychology of Changing Toward Future Responsive Societal Learning, Jossey-Bass, San Francisco (1973).

Received May 8, 1973 